\title{
Miscibility of Polybenzimidazole/Polyimidesulfone and Related Copolymers Blends
}

\author{
Doo Sung LEE* and Gyongyi QUIN \\ Department of Polymer Science and Engineering, University of Massachusetts, \\ Amherst, MA 01003, USA
}

(Received February 20, 1989)

\begin{abstract}
A series of blends of the aromatic polybenzimidazole, poly(2,2( $m$-phenylene)5,5'-benzimidazole) (PBI), and the aromatic polyimide-sulfone from 3,3',4,4'-benzophenone tetracarboxylic dianhydride (BTDA) and 3,3'-diaminodiphenylsulfone (3,3'DDS) (PISO) has been prepared by film casting from $N, N^{\prime}$-dimethylacetamide (DMAc) solution mixture. The differential scanning calorimetry, dynamic mechanical analysis and FT-IR spectroscopy were adapted to clarify the miscibility of PBI/PISO blends. The blends showed the single but very broad glass transition and this transition range was up to $110^{\circ} \mathrm{C}$ especially for $\mathrm{PBI} / \mathrm{PISO} 50 / 50 \mathrm{wt} \%$ blend by DSC measurement. The DSC thermograms were spread and shifted gradually to higher temperature with increasing times of run cycle which included annealing at 400 or $420^{\circ} \mathrm{C}$ without showing the phase separated transition even at last. The dynamic mechanical behavior showed the similar result with that of DSC and the evidence that the blends reacted more vigorously at above $420^{\circ} \mathrm{C}$ than the pure components due to catalytic activity of benzimidazole. From FT-IR spectra, the gradual linear shift of $\mathrm{N}-\mathrm{H}$ stretching band maxima as much as about $50 \mathrm{~cm}^{-1}$ was shown. But the phthalimide carbonyl and sulfone stretching band maxima showed little shift.

KEY WORDS High Temperature Polymer Blend / Polybenzimidazole /

Polyimidesulfone / $N, N^{\prime}$-dimethylacetamide / Miscibility / Phase Separation /

Specific Interaction / Crosslinking Reaction / Polyimidesulfone Copolymer /
\end{abstract}

Recently the novel polymer blends based on an aromatic polybenzimidazole (PBI) and an aromatic polyimides (PIs) has been reported. ${ }^{1-3}$ The blend pairs of PBI and several available PIs were studied (Table I). These polymer are all soluble in $N, N$-dimethylacetamide(DMAc) so that blends can be prepared by solution mixing, followed by film casting. The evidences for miscibility were presented by single $T_{\mathrm{g}}$ 's between the pure component $T_{\mathrm{g}}$ 's, well defined $\tan \delta$ relaxation peaks lying between those of component polymers, and the formation of optically clear transparent films.

Further study has focused on additional thermal studies of the properties and phase behavior of the blend combinations, and on FT-IR studies to obtain evidence for the existence of specific interactions related to their mutual miscibility and to elucidate the nature of these interactions. ${ }^{3}$ For blends of PBI with XU 218, Ultem 1000, PI 2080, and LaRC TPI, it was found that the criteria for miscibility listed above held for all four in all composition ranges although not necessarily over the entire accessible temperature regime. ${ }^{2-4}$ The IR studies showed composition changes in the spectral properties in the benzimidazole $\mathrm{N}-\mathrm{H}$ stretching band region of PBI and shifts in the phthalimide carbonyl bands of the PIs,

* To whom all correspondence should be addressed.

Present address: Department of Textile Engineering, Sung Kyun Kwan University, Suwon, Kyungki 440-746, Korea. 
Table I. Polymers studies in PBI/PI blend program

Chemical Name/[Source: Common Name $\left.\left(T_{\mathrm{g}}\right)\right] /$ Structure

(a) Poly (2,2'(m-phenylene)-5,5'-bibenzimidazole)

[Celanese Corporation: PBI $\left(T_{\mathrm{g}}=420^{\circ} \mathrm{C}\right)$ ]<smiles>Cc1cccc(-c2nc3cc(-c4ccc5[nH]c(C)nc5c4)ccc3[nH]2)c1</smiles>

(b) Poly[2,2'-bis (3,4-dicarboxyphenoxy) phenylpropane]-2-phenylene bisimide

[General Electric Company: Ultem $1000\left(T_{\mathrm{g}}=220^{\circ} \mathrm{C}\right)$ ]<smiles>Cc1cccc(N2C(=O)c3ccc(Oc4ccc(C(C)(C)c5ccc(Oc6ccc7c(c6)C(=O)N(C)C7=O)cc5)cc4)cc3C2=O)c1</smiles>

(c) Condensation product of 3,3',4,4'-benzophenone tetracarboxylic dianhydride (BTDA) and 5(6)amino-1-(4'-aminophenyl)-1,3,3-trimethylindane

[Ciba-Geigy Corporation: XU $218\left(T_{\mathrm{g}}=320^{\circ} \mathrm{C}\right)$ ]<smiles>Cc1ccc(C2(C)C(=O)c3ccc(N4C(=O)c5ccc(C(=O)c6ccc7c(c6)C(=O)N(C)C7=O)cc5C4=O)cc3C2(C)C)cc1</smiles>

(d) Condensation product of BTDA and a 4/I molar mixture of 2,4-toluene diisocyanate and 4,4'diphenylmethane diisocyanate

[Dow Chemical Co.: PI $2080\left(T_{\mathrm{g}}=310^{\circ} \mathrm{C}\right)$ ]<smiles>Cc1ccc(N2C(=O)c3ccc(C(=O)c4ccc5c(c4)C(=O)N(C)C5=O)cc3C2=O)cc1C1(C)C(=O)c2ccc(C(=O)c3ccc4c(c3)C(=O)N(c3ccc(C(C)(C)C)cc3)C4=O)cc2C1=O</smiles>

(e) Condensation product of $B T D \dot{A}$ and 3,3'-diaminobenzophenone (DABP)

[Mitsui Toatsu Chemicals, Inc.: LaRC TPI $\left(T_{\mathrm{g}}=267^{\circ} \mathrm{C}\right)$ ]<smiles>Cc1cccc(C(=O)c2cccc(N3C(=O)c4ccc(C(=O)c5ccc6c(c5)C(=O)N(C)C6=O)cc4C3=O)c2)c1</smiles>

(f) Condensation product of BTDA and 3,3'-diaminophenylsulfone (3,3'DDS)

[Our Laboratory: PISO $\left(T_{\mathrm{g}}=263^{\circ} \mathrm{C}\right)$ ]<smiles>Cc1cccc(S(=O)(=O)c2cccc(N3C(=O)c4ccc(C(=O)c5ccc6c(c5)C(=O)N(C)C6=O)cc4C3=O)c2)c1</smiles> 
that were related to $\mathrm{PBI} / \mathrm{PI}$ blend miscibility. ${ }^{3}$

The present work is on the blends formed from $\mathrm{PBI}^{5,6}$ and the polyimidesulfone (PISO) $)^{7,8}$ prepared from 3,3',4,4'-benzophenone tetracarboxylic dianhydride (BTDA) and 3,3'-diaminodiphenylsulfone (3,3'DDS) with the structure and $T_{\mathrm{g}}$ shown in Table I. This material has the excellent thermoplastic properties generally associated with polysulfones, and the solvent resistance and thermal stability of aromatic polyimides. This work was carried out to clarify the miscibility of PISO with PBI by using differential scanning calorimetry (DSC), dynamic mechanical thermal analysis (DMTA), Fourier transform infrared spectroscopy (FT-IR) and thermogravimetric analysis (TGA).

\section{EXPERIMENTAL}

\section{Materials}

Polybenzimidazole (PBI) powder from Celanese was dissolved in $N, N^{\prime}$-dimethylacetamide (DMAc) at $225^{\circ} \mathrm{C}$ for about $30 \mathrm{~min}$ in a high pressure vessel (Parr Pressure Reactor Inc.). The undissolved residue of about $0.2 \mathrm{wt} \%$ was left after filtration. The polymide sulfone (PISO) and related copolymers were synthesized in our laboratory from dianhydrides and diamines. The apparent number average molecular weight $\left(\bar{M}_{n}\right)$ of PISO which was measured by gel permeation chromatography and was calibrated by standard polystyrene was 690,000 . The $\bar{M}_{n}$ 's of PISO copolymers were in the range of 440,000 810,000 . These PISO and PISO copolymers were also dissolved in DMAc and filtered. The films were cast from about $3 \%(w / v)$ DMAc solution mixtures on the petri dishes under nitrogen at $80^{\circ} \mathrm{C}$ for 2 days. The cast films were washed in distilled water at $50^{\circ} \mathrm{C}$ for a week and dried in vacuum oven at $180^{\circ} \mathrm{C}$ for more than 2 weeks. The thin films (about $10 \mu \mathrm{m}$ ) for Fourier Transform Infrared Spectroscopy (FT-IR) and thick films (about $0.2 \mathrm{~mm}$ ) for Dynamic Mechanical Thermal Analysis
(DMTA) were prepared. The films were kept in the vacuum oven before testing.

\section{Measurements}

Differential scanning calorimetry experiments were carried out using a Perkin-Elmer DSC -7 controlled by a 7500 PC. The cycle of staying at $150^{\circ} \mathrm{C}$ for $5 \mathrm{~min}$, followed by scanning at $20^{\circ} \mathrm{C} \mathrm{min}^{-1}$ up to certain annealing temperature $\left(400,410,420^{\circ} \mathrm{C}\right.$, etc.) and then annealing for $5 \mathrm{~min}$ at that temperature, and cooling at $320^{\circ} \mathrm{C} \mathrm{min}^{-1}$ to $150^{\circ} \mathrm{C}$ was repeated several times to observe the phase separation process.

DMTA measurements were carried out using a Polymer Laboratory DMTA equipped with a high temperature $\left(500^{\circ} \mathrm{C}\right)$ head. Rectangular and about $0.2 \mathrm{~mm}$ thick test specimens were used. The constant strain $(\times 1)$ and frequency $(1 \mathrm{~Hz})$ in the flexural and single cantilever mode were applied under nitrogen flow. The scanning rate was $5^{\circ} \mathrm{C} \mathrm{min}^{-1}$ over a temperature range of 150 to $450^{\circ} \mathrm{C}$. The scanning was repeated several times to compare with DSC results.

An IBM IR/30 FT-IR spectrometer and thin cast films were used for the infrared spectral analysis. The sample was scanned from 400 to $4000 \mathrm{~cm}^{-1}$ under nitrogen atmosphere and the spectra were taken after 30 scans at a resolution of $2 \mathrm{~cm}^{-1}$.

A Perkin-Elmer TGA7 thermogravimetric analyzer was used to measure the thermal stability. The sample weight was about $10 \mathrm{mg}$. $\mathrm{N}_{2}$ flow rate was $60 \mathrm{ml} \mathrm{min}^{-1}$ and the heating rate was $20^{\circ} \mathrm{C} \mathrm{min}^{-1}$.

A Waters Model 200 gel permeation chromatography was used to measure the PISO and PISO copolymers synthesized in our laboratory. DMAc was used as solvent and flow rate was $1 \mathrm{ml} \mathrm{min}^{-1}$ at $40^{\circ} \mathrm{C}$.

\section{RESULTS AND DISCUSSION}

Figure 1 shows normalized thermograms of the second runs of the PBI/PISO 0/100, 25/75, 


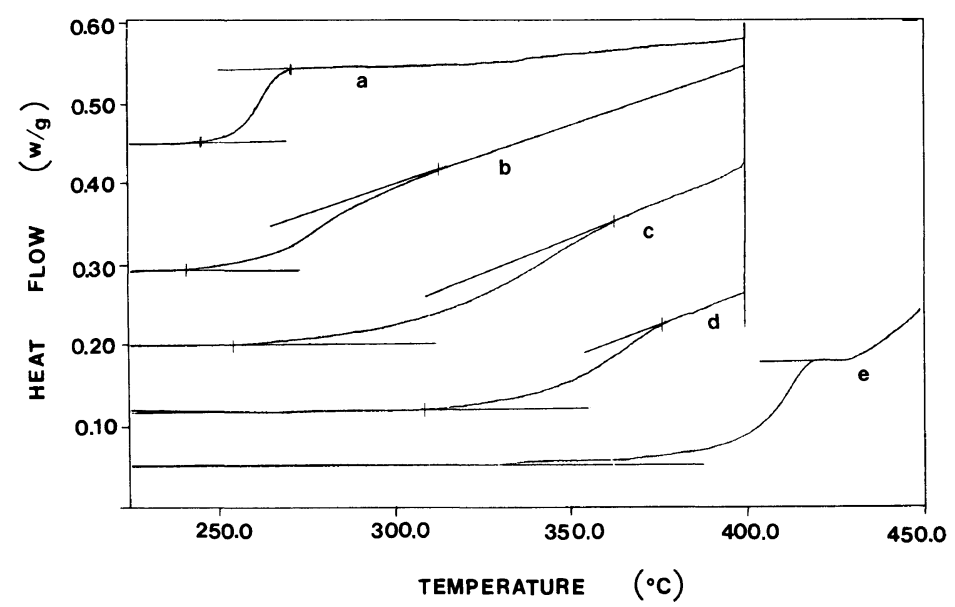

Figure 1. Normalized DSC thermograms of (a) $0 / 100 \mathrm{wt} \%$, (b) $25 / 75 \mathrm{wt} \%$, (c) $50 / 50 \mathrm{wt} \%$, (d) $75 / 25 \mathrm{wt} \%$, and (e) $100 / 0 \mathrm{wt} \% \mathrm{PBI} /$ PISO blends.

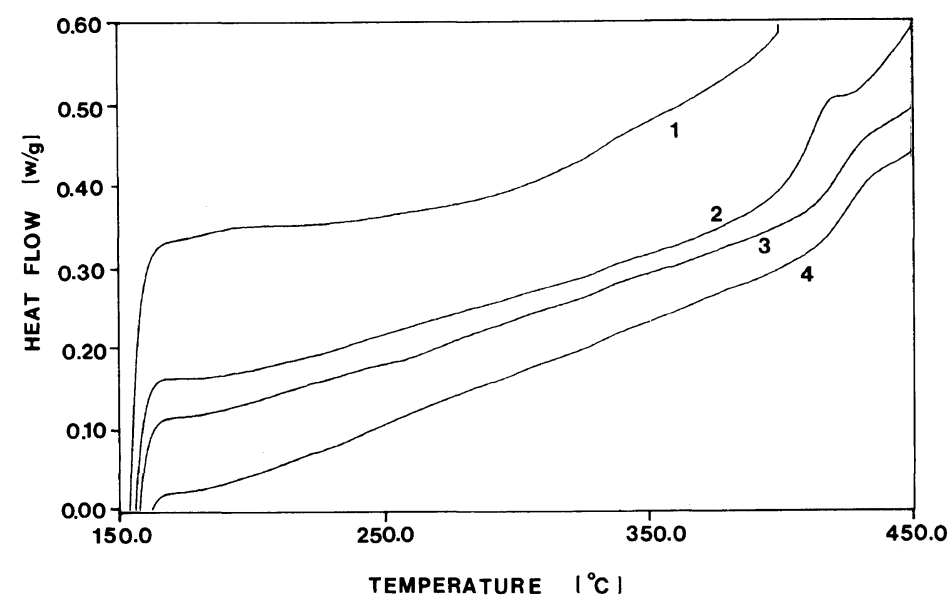

Figure 2. DSC thermogram of the pure PBI up to fourth scanning cycle.

$50 / 50,75 / 25$, and $100 / 0 \mathrm{wt} \%$ blend films after first run and annealing at $400^{\circ} \mathrm{C}$ for $5 \mathrm{~min}$. The transition temperature ranges of each samples show a relatively narrow range in case of pure component polymers, while the PBI/PISO $50 / 50 \%$ blends shows a very broad transition. The DSC thermograms of PBI $100 \%$ does not show typical transition due to several factors: existence of residual solvent due to lower annealing temperature than the $T_{\mathrm{g}}$ of PBI (about $420^{\circ} \mathrm{C}$ ), occurrence of chemical reaction such as crosslinking, completion of ring closing reaction, increase of molecular weight at higher temperature than $400^{\circ} \mathrm{C}$. At the next scan after this run and annealing at $450^{\circ} \mathrm{C}$ for $5 \mathrm{~min}$, typical glass transition which was similar to PISO was shown (Figure 2). The transition temperature ranges and glass transitions of the PBI/PISO blends are listed in Table II and Figure 3. The transition temperature ranges are calculated from $\Delta T=T_{\mathrm{f}}-T_{\mathrm{i}}$ which are described in Figure 4. The $T_{\mathrm{g}}$ 's were taken from the temperature which has same $\Delta C_{\mathrm{p}}$ from the parallel slopes. The range of 
glass transition show the maximum around $50 / 50 \mathrm{wt} \%$ and its value is about $110^{\circ} \mathrm{C}(255-$ $365^{\circ} \mathrm{C}$ ) (Figure 3). From these results, this system can be regarded as semi-compatible system.

The polymer blends which are immiscible each other in certain region show the phase separated two $T_{\mathrm{g}}$ 's after the annealing at higher temperature than the lower critical solution temperature (LCST). It is not shown in this system. The progress of phase change of the blends according to the repeated run as described in experimental section are shown in Figure 5. The DSC thermograms are spread and shifted gradually to higher temperature. In

Table II. Transition temperature ranges and glass transition temperatures of the PBI/PISO blends

\begin{tabular}{ccc}
\hline $\begin{array}{c}\text { PBI/PISO } \\
\text { composition } / \text { wt } \%\end{array}$ & $\begin{array}{c}\text { Transition } \\
\text { temperature } \\
\text { range } /{ }^{\circ} \mathrm{C}\end{array}$ & $\begin{array}{c}\text { Glass transition } \\
\text { temperature } /{ }^{\circ} \mathrm{C}\end{array}$ \\
\hline $0 / 100$ & 26 & 263 \\
$25 / 75$ & 72 & 281 \\
$50 / 50$ & 110 & 343 \\
$75 / 25$ & 68 & 365 \\
$100 / 0$ & $39^{\mathrm{a}}$ & 410 \\
\hline
\end{tabular}

a The data was taken from 3rd run because of abnormal second run. other words, the transition range is changed to broad and end point of transition increase according to the repeated runs, but still it

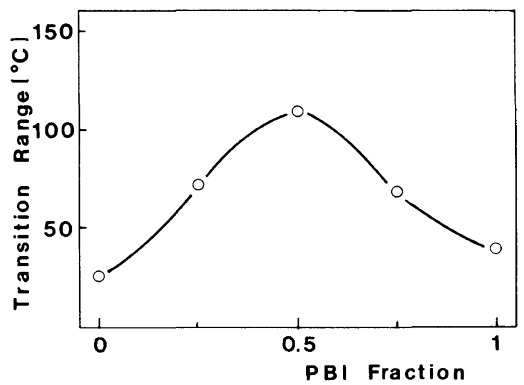

Figure 3. Glass transition temperature ranges $v s$. PBI fraction of the PBI/PISO blends.

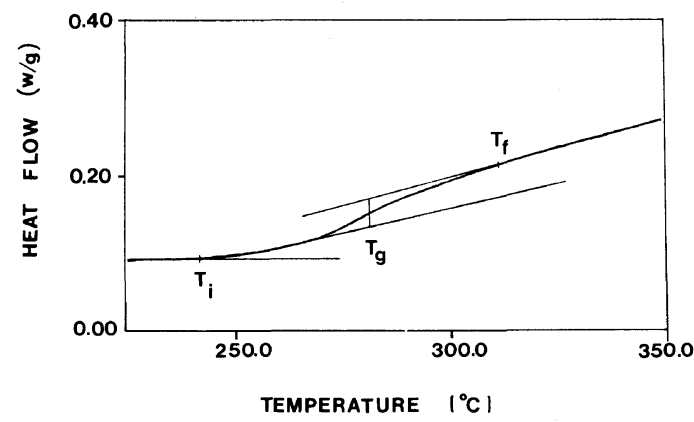

Figure 4. Schematic diagram of the determination of the $T_{\mathrm{g}}$ and the transition temperature range.

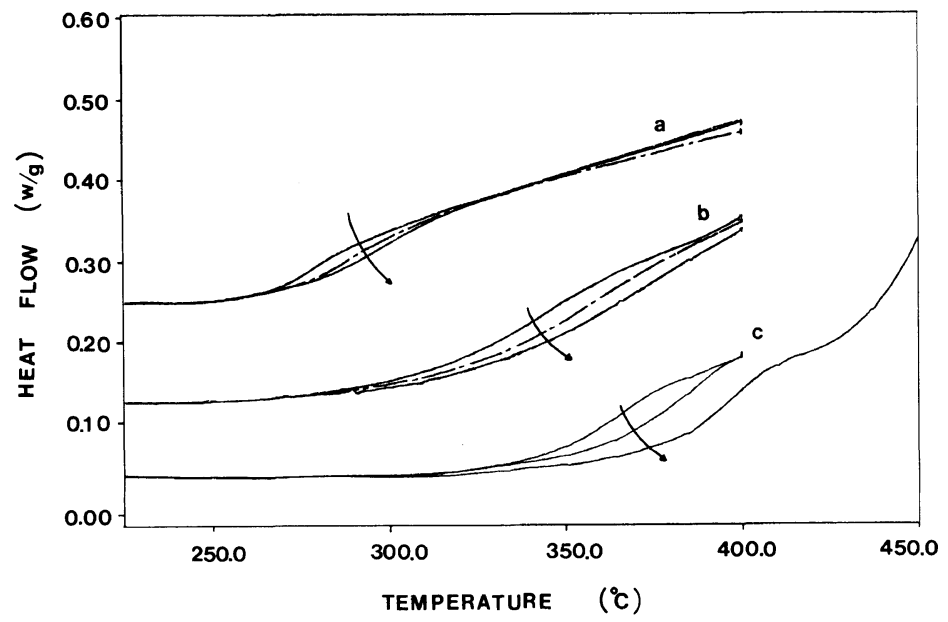

Figure 5. DSC thermograms of the repeated run of (a) second, fourth and sixth run of PBI/PISO $25 / 75 \mathrm{wt} \%$, (b) second, fourth and sixth run of PBI/PISO $50 / 50 \mathrm{wt} \%$, (c) second, fourth and seventh run of PBI/PISO $75 / 25 w \mathrm{t} \%$. 


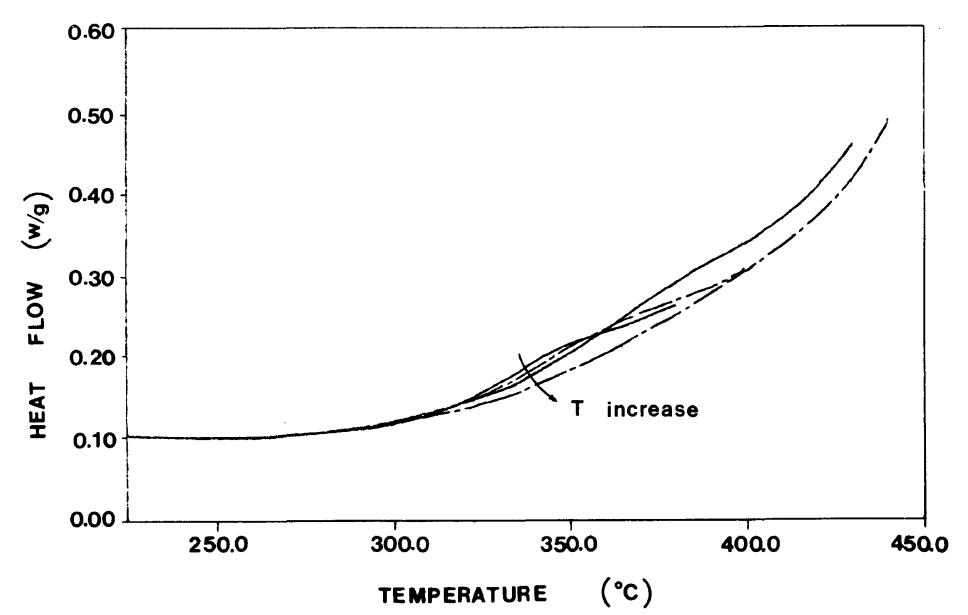

Figure 6. DSC thermograms after annealing temperature of $380,400,430$, and $440^{\circ} \mathrm{C}$.

seems to be at homogeneous state. It might exist some specific interaction between PBI and PISO. The change of transition with increasing the times of run is more significant in case of higher content of PBI, i.e., PBI/PISO $75 / 25 \mathrm{wt} \%$ blend. The driving force of phase separation takes some role in this change of transition range besides the removal of solvent and the crosslinking reaction. The crosslinked structure can increase the $T_{\mathrm{g}}$ of the blend polymer itself, but it can also prevent the phase separation of the polymer blends as illustrated in the interpenetrating polymer network (IPN) systems. ${ }^{9}$ The $T_{\mathrm{g}}$ of $\mathrm{PBI}$ is changed abruptly ${ }^{10}$ by annealing for $20 \mathrm{~min}$ between $400^{\circ} \mathrm{C}$ and $420^{\circ} \mathrm{C}$ due to the structure change such as crosslinking reaction and solvent removal around its own $T_{\mathrm{g}}$. And the PBI can not be dissolved again perfectly after annealing at above $380^{\circ} \mathrm{C}$ for $20 \mathrm{~min}$ due to crosslinking.

The Figure 6 shows second runs after first run followed by annealing at 380, 400, 430, and $440^{\circ} \mathrm{C}$ for $5 \mathrm{~min}$. The shape of transition are changed to broad to high temperature with increasing annealing temperature. And the transition is not shown after annealing at $440^{\circ} \mathrm{C}$, and the thermogram increase monotonically. Moreover, the third run after annealing at $430^{\circ} \mathrm{C}$ one more time for $5 \mathrm{~min}$ was also shown monotonical increase and no

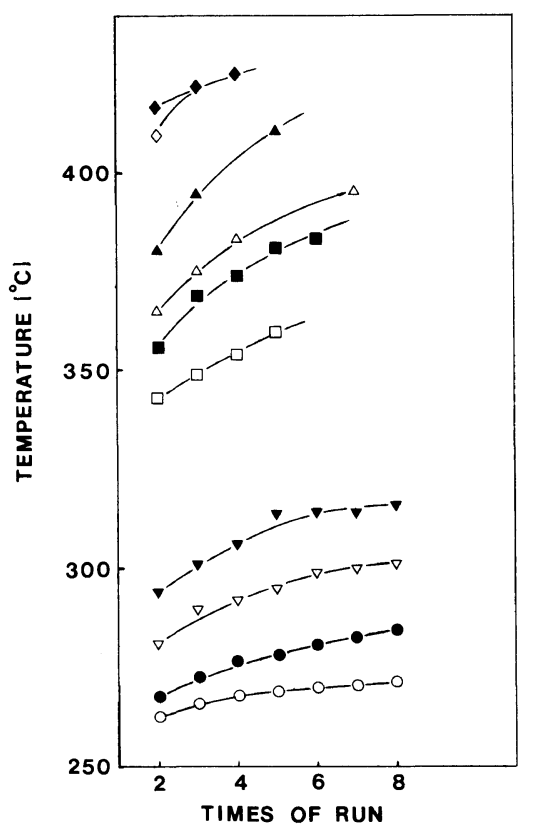

Figure 7. Glass transition temperature $v s$. times of run cycle of $\bigcirc, \boldsymbol{O}, 0 / 100 \mathrm{wt} \% ; \nabla, \boldsymbol{\nabla}, 25 / 75 \mathrm{wt} \% ; \square, \square$, $50 / 50 \mathrm{wt} \% ; \triangle, \Delta, 75 / 25 \mathrm{wt}^{\circ} \% ; \diamond, \diamond, 100 / 0 \mathrm{wt} \%$ of the $\mathrm{PBI} / \mathrm{PISO}$ blends (the annealing temperature of open symbol and closed symbol are $400^{\circ} \mathrm{C}$ and $420^{\circ} \mathrm{C}$, respectively).

transition. The reason why the transition is hardly shown is that there is a vigorous reaction at high temperature as mentioned before and so the polymer segment is hardly 
moved as the highly crosslinked materials, furthermore the chains of two component polymers are extremely stiff.

Figure 7 show the change of the glass transition temperature according to the repeated run after annealing at $400^{\circ} \mathrm{C}$ or $420^{\circ} \mathrm{C}$ at the end of each run. The $T_{\mathrm{g}}$ was determined as described in Figure 4. The $T_{\mathrm{g}}$ of PISO after annealing at $420^{\circ} \mathrm{C}$ increases gradually from $268^{\circ} \mathrm{C}$ to $285^{\circ} \mathrm{C}$ with increasing the times of run. It means that the chemical structure is affected during annealing at $420^{\circ} \mathrm{C}$. On the other hand, the $T_{\mathrm{g}}$ of PISO annealed at $400^{\circ} \mathrm{C}$ shows a relatively little change. As mentioned before, the $T_{\mathrm{g}}$ of PBI is changed abruptly between the annealing temperature of $400^{\circ} \mathrm{C}$ and $420^{\circ} \mathrm{C}$ due to the structure change such as crosslinking reaction and solvent removal at around its own $T_{\mathrm{g}}$. The difference of $T_{\mathrm{g}}$ between the annealing temperature of $400^{\circ} \mathrm{C}$ and $420^{\circ} \mathrm{C}$ is approximately $15-20^{\circ} \mathrm{C}$ and the shape of change is similar in all blends composition. This difference of $T_{\mathrm{g}}$ change is seemed to be resulted from the difference of the degree of structure change and of the driving force of phase separation. The polymer blends of high content of PBI shows more significant change in $T_{\mathrm{g}}$ by annealing than the blends of lower content of PBI as shown in Figure 5. This change is significantly bigger than the estimated average based on the weight fraction and the change of each pure component. There can be several reason for the above result: the first, the method of $T_{\mathrm{g}}$ determination based on the parallel slope may take some role on increasing the $T_{\mathrm{g}}$ of blends of the high content of PBI more than that of blends of the lower content of PBI, the second, the phase separation may be also progressed to some degree during repeated run, the third, the intermolecular reaction between PBI and PISO is more vigorous at certain composition than each pure component polymers themselves, so that crosslinking resulted from intermolecular reaction can increase the $T_{\mathrm{g}}$ higher than that of others. It should be noted that the phase separation is very difficult due to crosslinking of component polymers and extremely high stiffness of polymer chains as well as the specific interaction between PBI and PISO.

Figures 8-10 show the dynamic mechanical properties of PBI/PISO blends. The PISO pure polymer and blends film of PBI/PISO $25 / 75 \%$ are too brittle to be tested. The first and second

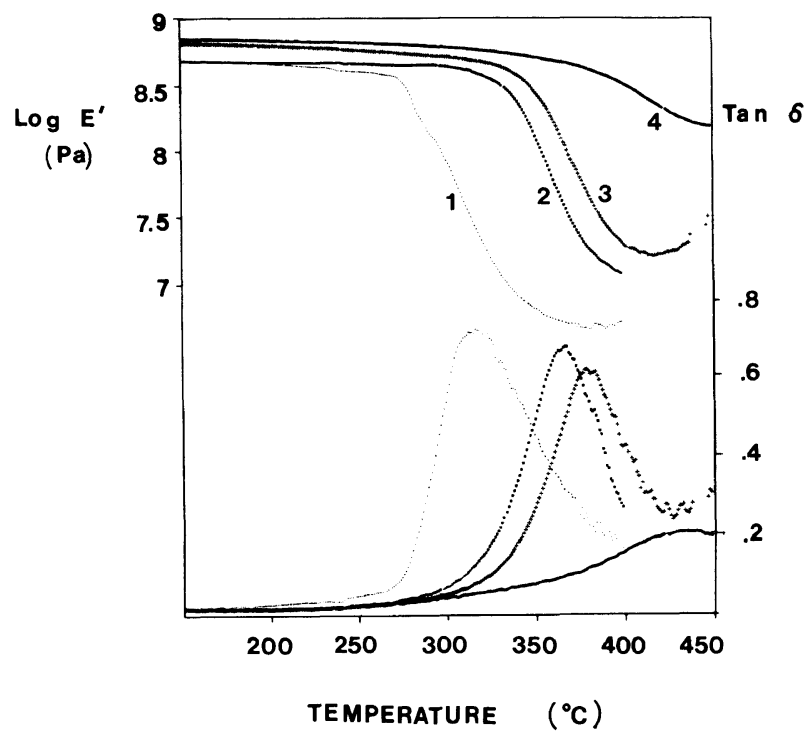

Figure 8. Dynamic mechanical properties of the PBI/PISO $50 / 50 \mathrm{wt} \%$ blend up to fourth run. 


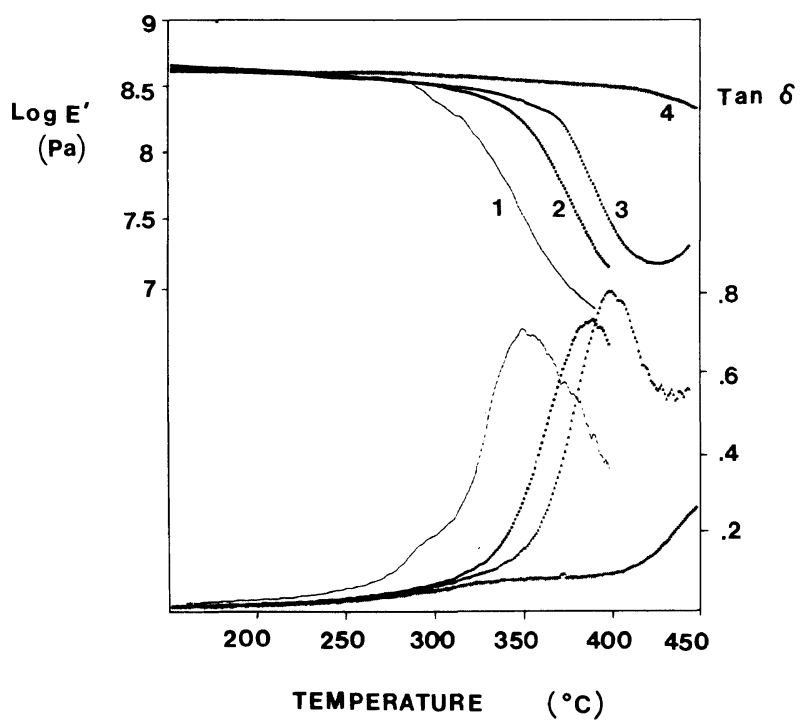

Figure 9. Dynamic mechanical properties of the PBI/PISO $75 / 25 \mathrm{wt} \%$ blend up to fourth run.

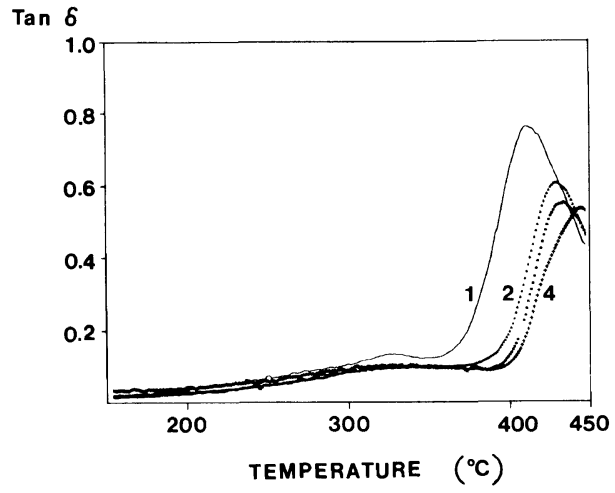

Figure 10. Dissipation factor of the PBI up to fourth run.

runs of the blends were tested up to $400^{\circ} \mathrm{C}$ and the third and fourth runs were tested up to $450^{\circ} \mathrm{C}$. The $\tan \delta$ of $\mathrm{PBI} / \mathrm{PISO}$ blends are shifted to high temperature according to the repeated run. The storage moduli are shifted also and are shown like a homogeneous blend until the third run. But it must be noted that the transition ranges are very wide and the transition are shifted a lot of degrees at each run. At the third run, the storage modulus begin to increase at about $420^{\circ} \mathrm{C}$ and the $\tan \delta$ does not decrease any more. It is because of

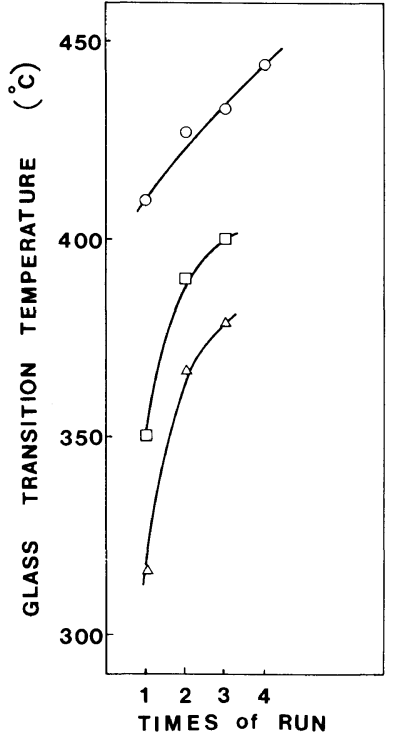

Figure 11. Glass transition change determined by $\tan \delta$ peak of the $\triangle, 50 / 50 \mathrm{wt} \% ; \square, 75 / 25 \mathrm{wt} \% ; \bigcirc, 100 / 0 \mathrm{wt} \%$ PBI/PISO blends.

structure change such as crosslinking as mentioned before. At the fourth run, the polymer blends show the behavior as highly crosslinked materials, and the large change is in $\tan \delta$ curve. In the case of PBI $100 \%$ film, the four times of run were all scanned up to $450^{\circ} \mathrm{C}$. But 


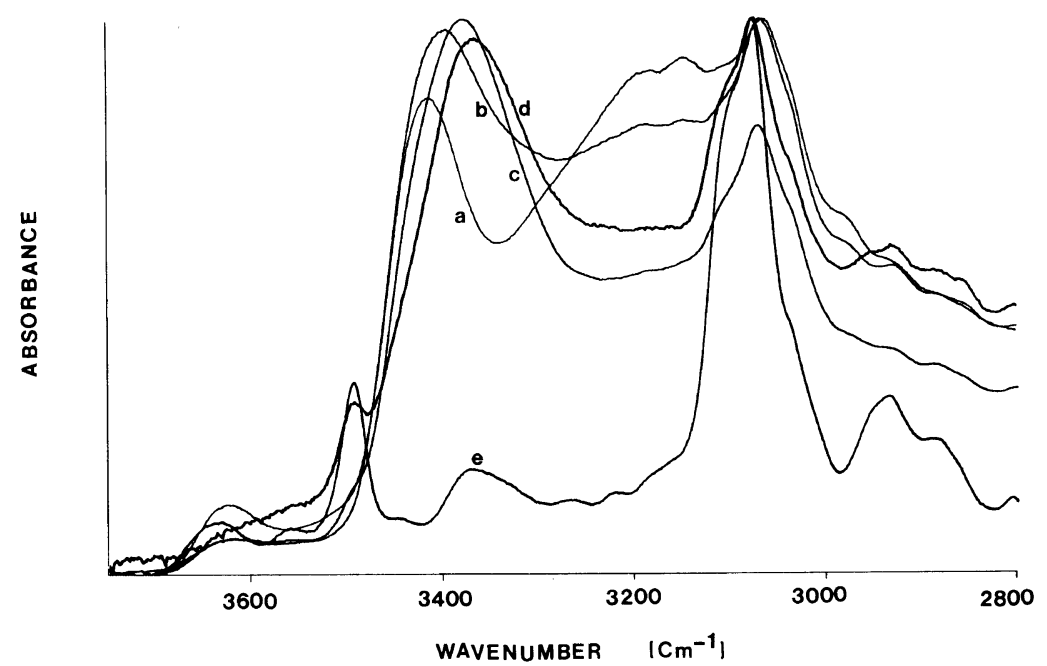

Figure 12. Fourier transform infrared spectra of (a) $100 / 0 \mathrm{wt} \%$, (b) $75 / 25 \mathrm{wt}^{\circ} \%$, (c) $50 / 50 \mathrm{wt} \%$, (d) $25 / 75 \mathrm{wt} \%$, and (e) $0 / 100 \mathrm{wt} \% \mathrm{PBI} / \mathrm{PISO}$ blends.

no significant change is shown except little shift in $T_{\mathrm{g}}$ and decrease of damping (Figure 10). It is noted that there is vigorous intermolecular crosslinking reaction between $\mathrm{PBI}$ and PISO which precise mechanism is not known. The $T_{\mathrm{g}}$ which are taken from peak point of $\tan \delta$ are shown in Figure 11. The thermal aging effect is more significant than DSC because the scanning rate of DMTA is slower than that of DSC, the mechanical moving may help to remove the residual solvent and some thermal gradient may exist between the DMTA clamping part and the thermocouple.

From the DSC and DMTA results, it was shown that some specific interactions might exist between PBI and PISO. Evidence for the specific interactions between $\mathrm{PBI}$ and PISO can be found in the regions of $\mathrm{N}-\mathrm{H}$, aromatic $\mathrm{C}-\mathrm{H}$ and carbonyl stretching bands which are shown at about 3400,3065 , and $1700 \mathrm{~cm}^{-1}$, respectively. ${ }^{11}$ The spectra of the samples are shown in Figure 12. The peaks at about 3410 and $3062 \mathrm{~cm}^{-1}$ are assigned to $\mathrm{N}-\mathrm{H}$ and aromatic $\mathrm{C}-\mathrm{H}$ stretching bands, respectively. The maximum peaks of $\mathrm{N}-\mathrm{H}$ stretching band are shifted about $50 \mathrm{~cm}^{-1}$ linearly from $3412 \mathrm{~cm}^{-1}$ to $3363 \mathrm{~cm}^{-1}$ with decreasing PBI fraction and

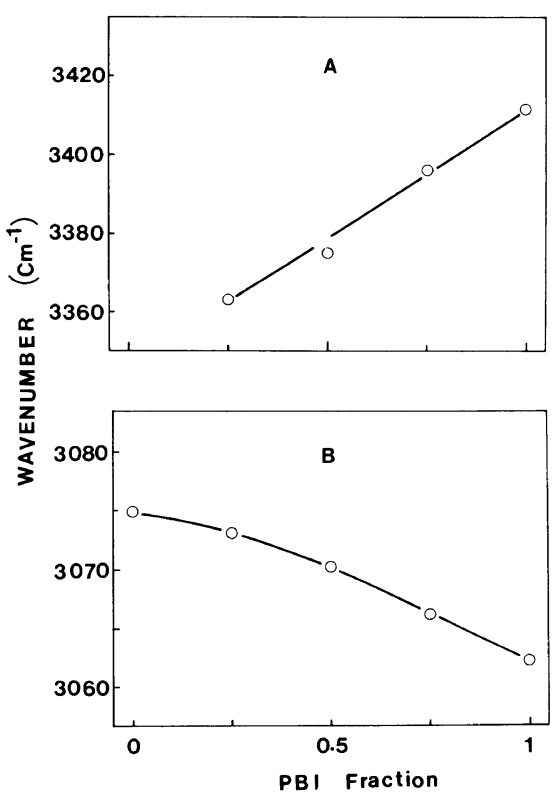

Figure 13. Location of the maxima vs. PBI fraction of (A) the $\mathrm{N}-\mathrm{H}$ stretching band of $\mathrm{PBI}$ and (B) the aromatic $\mathrm{C}-\mathrm{H}$ stretching band of the $\mathrm{PBI} / \mathrm{PISO}$ blends.

this is shown in Figure 13A. The maxima of aromatic $\mathrm{C}-\mathrm{H}$ stretching bands of PBI-PISO blends are shown in Figure 13B. The maxima is shifted gradually from $3075 \mathrm{~cm}^{-1}$ of PISO to $3062 \mathrm{~cm}^{-1}$ of PBI with increasing PBI content. Although the concentrations of the aromatic 
$\mathrm{C}-\mathrm{H}$ in the blends are changed a little according to the composition change of the PBI, the ratio of the absorbance of $\mathrm{N}-\mathrm{H}$ stretching band and aromatic $\mathrm{C}-\mathrm{H}$ stretching band shows the maximum at $50 \mathrm{wt} \%$ of $\mathrm{PBI}$ and is shown in Figure 14. This means that the maximum amount of $\mathrm{N}-\mathrm{H}$ has specific interaction with others at $50 \mathrm{wt} \%$ of PBI. And the reason why the $\mathrm{N}-\mathrm{H}$ band peak of $25 \mathrm{wt} \%$ of $\mathrm{PBI}$ is more shifted than $50 \mathrm{wt} \%$ of $\mathrm{PBI}$ is that the other kind of interaction of $\mathrm{N}-\mathrm{H}$ is more efficient at low fraction of PBI. The peaks of the principal phthalimide carbonyl stretching bands and sulfone stretching bands of PISO show little

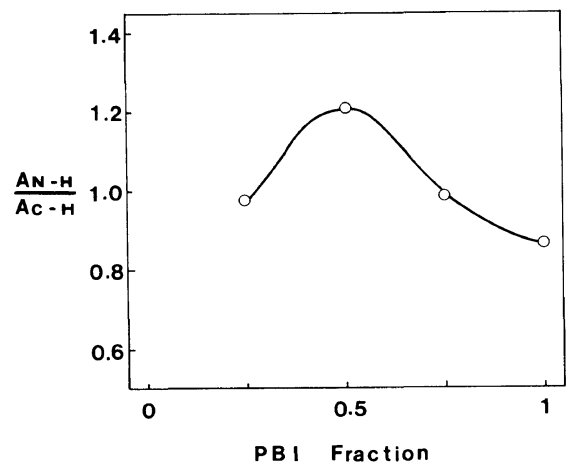

Figure 14. Absorbance ratio of the $\mathrm{N}-\mathrm{H}$ stretching band and aromatic $\mathrm{C}-\mathrm{H}$ stretching band as a function of PBI fraction. shift $\left(3 \mathrm{~cm}^{-1}\right.$ and $2 \mathrm{~cm}^{-1}$, respectively) (Table III). In the case of PBI and XU $218^{3}$ (CibaGeigy Corp.) blends system, the maximum peaks of $\mathrm{N}-\mathrm{H}$ stretching band were shifted to lower wavenumbers up to maximum of $55 \mathrm{~cm}^{-1}$ at $50 \mathrm{wt}^{\mathrm{o}} \mathrm{XU} 218$ and stayed at that value. And the phthalimide $\mathrm{C}=\mathrm{O}$ stretching bands were shifted up to $6 \mathrm{~cm}^{-1}$ and were also shown the plateau region. The three possible source of interaction was proposed ${ }^{3}$ : (a) $\pi$ orbital interaction between the imide and imidazole rings, (b) a charge transfer interaction between the phthalimide and benzimidazole fused-ring systems, or (c) hydrogen bonding between the carbonyl group and the 'NH group. Further studying about the specific interaction of these systems are carrying out

Table III. Maxima of carbonyl and sulfone stretching bands of the PBI/PISO blends measured by FT-IR

\begin{tabular}{|c|c|c|c|c|}
\hline \multirow{2}{*}{$\begin{array}{c}\begin{array}{c}\mathrm{PBI} / \mathrm{PISO} \\
\text { composition }\end{array} \\
\mathrm{wt} \%\end{array}$} & \multirow{2}{*}{\multicolumn{2}{|c|}{$\begin{array}{l}\text { Carbonyl stretching } \\
\text { bands } \\
\frac{\mathrm{cm}^{-1}}{}\end{array}$}} & \multirow{2}{*}{\multicolumn{2}{|c|}{$\begin{array}{l}\text { Sulfone stretching } \\
\text { bands } \\
\frac{\mathrm{cm}^{-1}}{}\end{array}$}} \\
\hline & & & & \\
\hline $0 / 100$ & 1782.4 & 1724.6 & 1367.7 & 1157.4 \\
\hline $25 / 75$ & 1782.4 & 1725.5 & 1369.6 & 1158.4 \\
\hline $50 / 50$ & 1781.5 & 1727.5 & 1368.7 & 1157.4 \\
\hline $75 / 25$ & 1781.5 & 1727.5 & 1367.7 & 1156.5 \\
\hline $100 / 0$ & - & - & - & - \\
\hline
\end{tabular}

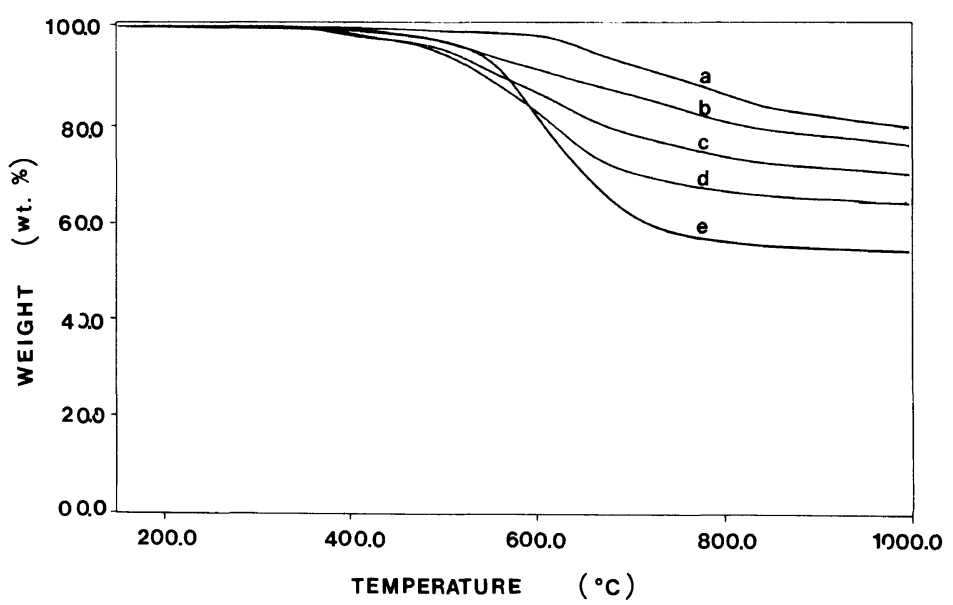

Figure 15. TGA thermograms of the PBI/PISO (a) $100 / 0 \mathrm{wt}^{\circ} \%$, (b) $75 / 25 \mathrm{wt} \%$, (c) $50 / 50 \mathrm{wt} \%$, (d) $25 / 75$ $w t \%$, and (e) $0 / 100 w t \%$ blends. 
Table VI. Glass transition temperatures of PISO copolymers and blends of PBI-PISO copolymer Dianhydrides<smiles>CN1C(=O)c2ccc(C(=O)c3ccc4c(=O)n(C)n(C)c(=O)c4c3)cc2C1=O</smiles>
Diamines

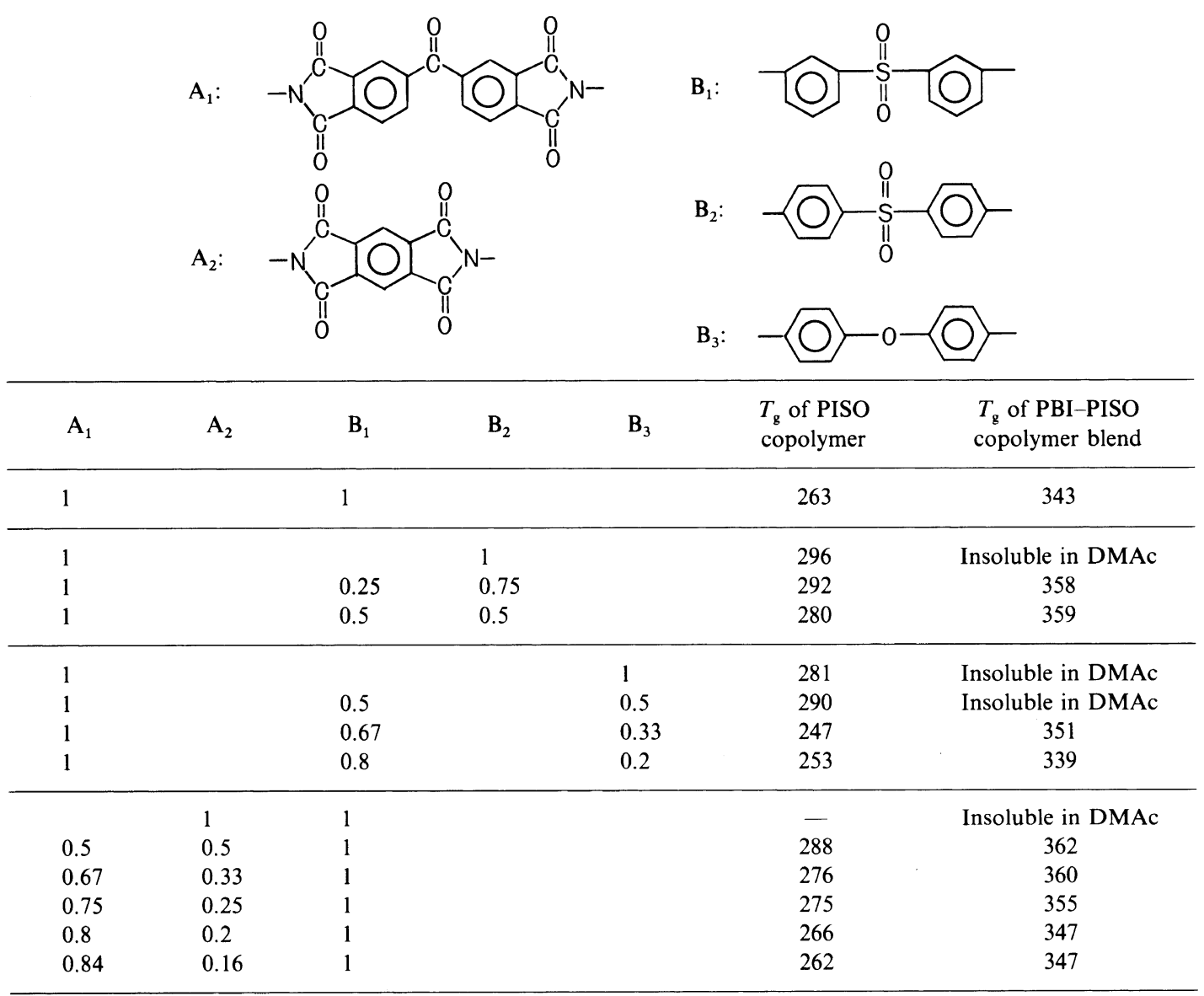

a All $T_{\mathrm{g}}$ 's were taken from second scan after first scan and annealing at $400^{\circ} \mathrm{C}$ for $5 \mathrm{~min}$.

to clarify the precise nature of the contributions to the overall interaction by the spectroscopic and the other methods.

The thermal stability in nitrogen atmosphere measured by TGA is shown in Figure 15. The thermal stability of PBI and PISO is very good. Their weight retentions are about $80 \%$ and $55 \%$ at $1000{ }^{\circ} \mathrm{C}$, respectively. It can be estimated that these polymers are changed to heterocyclic compound which is stable at high temperature and eventually to carbonized material. The blends of PBI-PISO show the midrange thermal stability between the two pure components and their stability are enhanced a little than the expected values based on the weight fractions of the two component.

Table IV shows the $T_{\mathrm{g}}$ of the PISO copolymers and the blends of PBI-PISO copolymer. The polyimides which consist of following dianhydrides and diamines; $A_{1} B_{2}, A_{1} B_{3}$, and $A_{2} B_{1}$ of Table IV, are insoluble in DMAc. It means that these polymers seem to have different solubility parameters from PBI which can be dissolved in DMAc. Therefore, PISO copolymers which consist of $A_{1} B_{1}$ (original PISO) with one of above three polyimides were tested to observe the phase separation behavior and phase diagram at low temperature, 
if it is possible. From the series of copolymers, it was observed that all the PISO copolymers of any composition which can be dissolved in DMAc are miscible with PBI as like as PISO. The ranges of glass transition are also similar to that of PISO. It can be thought that the insolubility in DMAc (e.g., insoluble PISO copolymer) does not mean immiscibility with PBI. On the other hand, the polymer pair even in cosolvent can be frequently immiscible after casting.

Acknowledgements. This research was supported by the Korea Science and Engineering Foundation. This research was supported also by the Advanced Research Projects Agency of the Department of Defense and was monitored by the Air Force of Scientific Research under Contract No. F49620-85-0127.

\section{REFERENCES}

1. L. Leung, D. J. Williams, F. E. Karasz, and W. J.
MacKnight, Polym. Bull., 16, 1457 (1986).

2. S. Stankovic, G. Guerra, D. J. Williams, F. E. Karasz, and W. J. MacKnight, Polym. Commun., 29, 14 (1988).

3. G. Guerra, S. Choe, D. J. Williams, F. E. Karasz, and W. J. MacKnight, Macromolecules, 21, 231 (1988).

4. G. Guerra, D. J. Williams, F. E. Karasz, and W. J. MacKnight, submitted for publication.

5. H. Vogel and C. S. Marvel, J. Polym. Sci., 50, 551 (1961).

6. G. M. Moelter, R. F. Tetreault, and M. J. Hefferson, Polymer News, 9, 134 (1983).

7. T. L. St. Clair and D. A. Yamaki, in "Polyimides," K. L. Mittal, Ed., Plenum, New York, N. Y., 1984, p 99.

8. T. L. St. Clair and D. A. Yamaki, U.S. Patent 4,398,021, Aug. 9, 1983.

9. L. H. Sperling, "Intepenetrating Polymer Networks and Related Materials," Plenum Press, New York, N. Y., 1981.

10. K. Liang, F. E. Karasz, and W. J. MacKnight, unpublished data.

11. C. J. Pouchert, Ed., "The Aldrich Library of Infrared Spectra," 3rd ed, Aldrich Chemical Co., Inc., Milwaukee, WI, 1981. 